\title{
Ações coletivas: Evolução e desafios para uma perspectiva transformadora da jurisdição à luz do princípio do acesso à justiça e da duração razoável do processo
}

\author{
Collective actions: Evolution and challenges for a transformative perspective of jurisdiction in the
} light of the principle of access to justice and the reasonable duration of the process

Acciones colectivas: Evolución y desafíos para una perspectiva transformadora de la jurisdicción a la luz del principio de acceso a la justicia y la duración razonable del proceso

Juscelino Pires da Fonseca ORCID: https://orcid.org/0000-0003-2115-5688 Universidade Paranaense, Brasil E-mail: juscelinoadvocacia@gmail.com

Jônatas Luiz Moreira de Paula ORCID: https://orcid.org/0000-0001-6408-0394 Universidade Paranaense, Brasil E-mail: jlmp@onda.com.br Kelly Cardoso ORCID: https://orcid.org/0000-0002-0216-9809 Universidade Paranaense, Brasil E-mail:servjuskelly@gmail.com

\begin{abstract}
Resumo
O presente trabalho tem como objetivo analisar alguns aspectos das denominadas ações coletivas atinentes a evolução de seus conceitos e as discussões atuais da doutrina sob seus temas centrais. A proposta é apresentar historicamente a evolução do processo coletivo como um novo processo civil, indispensável à um acesso à justiça substancial aos jurisdicionados, na medida em que mescla a celeridade e economia processual, assegurando igualdade, isonomia e duração razoável do processo. Medida que promove a concretização efetiva de direitos fundamentais de uma sociedade contemporânea que intenta ter suas acepções atendidas. Para tanto, utiliza-se da metodologia dedutiva em análise bibliográfica e legislativa para tecer a tese argumentativa da importância das ações coletivas à pacificação social.
\end{abstract}

Palavras-chave: Processo coletivo; Celeridade; Acesso à justiça; Direitos fundamentais.

\begin{abstract}
The present work aims to analyze some aspects of the so-called collective actions concerning the evolution of its concepts and the current discussions of the doctrine under its central themes. The proposal is to present historically the evolution of the collective process as a new civil process, indispensable to the access to substantial justice to the jurisdictional ones, inasmuch as it mixes the speed and procedural economy, ensuring equality, equality and reasonable duration of the process. Measure that promotes the effective realization of fundamental rights of a contemporary society that tries to have its meanings met. For that, it uses the deductive methodology in bibliographic and legislative analysis to make the argumentative thesis of the importance of collective actions to social pacification.
\end{abstract}

Keywords: Collective process; Celerity; Access to justice; Fundamental rights.

\section{Resumen}

El presente trabajo tiene como objetivo analizar algunos aspectos de las llamadas acciones colectivas en torno a la evolución de sus conceptos y las discusiones actuales de la doctrina bajo sus temas centrales. La propuesta es presentar históricamente la evolución del proceso colectivo como un nuevo proceso civil, indispensable para el acceso a la justicia sustancial a los jurisdiccionales, en la medida en que mezcla la celeridad y la economía procesal, asegurando igualdad, equidad y duración razonable del proceso. . Medida que promueve la efectiva realización de los derechos fundamentales de una sociedad contemporánea que intenta que sus significados se cumplan. Para ello, utiliza la metodología deductiva en el análisis bibliográfico y legislativo para realizar la tesis argumentativa de la importancia de las acciones colectivas para la pacificación social.

Palabras clave: Proceso colectivo; Celeridad; Acceso a la justicia; Derechos fundamentales. 


\section{Introdução}

Este trabalho se propõe a analisar as Ações Coletivas sob o enfoque de sua evolução histórica e conceitual, com os desafios atinentes a formação de uma nova perspectiva de processo civil, na qual originaram-se várias codificações, tendo como marcos principais a Lei de Ação Civil Pública (1985) a Constituição Federal (1988) e o Código de Defesa do Consumidor (1990).

Além disso, busca-se apresentar formulações de que o Sistema Processual Coletivo ampliou o acesso à justiça, principalmente porque tendo em vista o dinamismo da sociedade contemporânea caracterizada por relações jurídicas e sociais complexas, os conflitos de massa se apresentaram como um problema que não poderia ser solucionado pelo tradicional processo civil individual, calcado na defesa dos interesses particulares.

Por fim, tratar-se-á de preocupações com enquadramentos conceituais equivocados e das principais divergências sobre esta matéria na atualidade, que entende-se só serão amenizadas com a criação de um Código de Processo Coletivo e o abandono pelos cientistas dos direitos da contumaz tentativa de enquadramento do processo coletivo aos procedimentos existentes e tão conhecidos do processo individual.

Ademais, durante a pesquisa realizada demonstra-se a importância desta ciência, para fins de economia, celeridade processual, proteção de grupos, classes e minorias que poderão ter suas aspirações atendidas com relação jurídica em patamar de igualdade com os pretensos violadores destes direitos, sempre calcado na busca pela concretização de direitos fundamentais e da tutela jurisdicional.

\section{Metodologia}

A pesquisa foi permeada pela explanação das premissas extraídas da legislação e da revisão bibliográfica, num constructo metodológico dedutivo. Segundo Marconi e Lakatos (2003, p. 92) o método dedutivo "tem o propósito de explicar o conteúdo das premissas", como meio de obter os resultados da conclusão.

Para tanto, parte-se da descrição evolutiva histórica do processo coletivo, como meio garantidor do acesso à justiça, utilizando-se de doutrinadores que contribuem para a comprovação concatenada do processo evolutivo.

Para a utilização de premissas a conceituação, os requisitos e a relevância das ações coletivas, bem como, a necessidade de estabelecer um regramento específico e adequado ao processo coletivo.

\section{Resultados e Discussões}

\subsection{Evolução do processo coletivo como garantia de acesso à justiça}

O Acesso à Justiça não existia no direito natural, posto que apenas com o surgimento do Estado de Direito, um terceiro imparcial passou a desempenhar as funções de dirimir conflitos e impor coercitivamente suas decisões. No Estado Liberal, assim definido como de culto a literalidade da lei, também não houve muito avanço, pois era assegurado apenas um acesso à justiça formal e não efetivo (Capeletti, et. al., 1988, p.9).

O Estado Liberal foi criado com intuito de limitar a atuação do monarca, consagrando o princípio da legalidade. O problema é que tal abordagem excluía de sua apreciação os direitos sociais até porque a influência do Iluminismo racionalista, atrelado ao dogma de completude impedia a interpretação da lei, que aplicada em sua literalidade buscava ideais de segurança jurídica, mas afastava os jurisdicionados de uma participação efetiva, comprometendo o primado do acesso à justiça a privilegiar uma visão reducionista do direito (Souza Netto, 2012, p. 5). 
No mesmo sentido Capeletti e Garth (1988, p. 11-12), já diziam que o acesso à justiça estava em uma crescente de desenvolvimento, que novos direitos individuais e sociais surgiam e que seria necessário mecanismos para sua reivindicação, sob pena de não ter sentido ser titular desses direitos, se não há como buscar sua implementação.

Com a mudança do Estado Liberal para o Estado Constitucional a concepção de acesso à justiça sofre grande transformação posto que a jurisdição passa a se utilizar de princípios e regras constitucionais, para interpretação do direito possibilitando ao cidadão um acesso mais amplo ao judiciário.

Devido ao dinamismo da sociedade faz-se necessário a adaptação dos textos normativos. A própria ideia da utilização de princípios já demonstrava imprecisão e limitação das regras como forma única de resolver conflitos e garantir o acesso à justiça. Surgiu a necessidade do direito ser visto como um instrumento de transformação social, mas para isso é necessário que se compreenda a realidade (Souza Netto, 2012, p. 29).

Nesse contexto, surgiram conflitos que não encontravam amparo lógico-racional e jurídico na legislação codificada, necessitando de leis específicas a preverem tais comportamentos e com isso surgiu no Brasil com inspiração nos trabalhos do jurista Italiano Mario Capeletti a Lei da Ação Civil Pública (Lei7.347/85), marco da origem do direito coletivo no Brasil.

Nessa época (meados da década de 1980) o Processo Civil Brasileiro era atingido pela segunda onda renovatória de origem romano-germânica, que tinha como objetivo o tradicionalismo processual de cunho individualista (Dinamarco, 1999, p. $155)$.

A preocupação da segunda onda renovatória, era demonstrar a lacuna do ordenamento jurídico processual, logo sua incapacidade de proteger os direitos coletivos, tendo em vista estar cunhado em uma relação de disputas entre particulares, para resolver seus próprios interesses, portanto uma visão individualista inapropriada para solucionar conflitos de massa, portanto de concepção social e coletiva.

Segundo Capelletti e Garth (1988, p.12), diante da impossibilidade de todos os titulares de determinado direito difuso (ex: qualidade do ar) deduzirem suas pretensões em juízo, a solução seria nomear um "representante adequado", que agiria em benefício dos pretensos afetados, sendo que ao fim a decisão judicial obrigaria a todos os membros da coletividade, protegendo os direitos difusos, importando em uma necessidade de alteração da noção tradicional de coisa julgada.

Conforme Zavascki (2016, p. 13) as modificações no sistema processual ocorreram em duas fases, a primeira iniciada com a Lei de Ação Civil Pública, portanto com a introdução no direito positivo de mecanismos processuais desconhecidos atento a nova roupagem do direito processual que se agigantava por meio das ações coletivas, "tutelando direitos e interesses transindividuais e a própria ordem jurídica abstratamente considerada". A segunda fase iniciou na década de 1990, especificamente a partir de 1994, com objetivo de aperfeiçoar e ampliar os instrumentos processuais existentes no Código de Processo Civil de 1973, já que a sociedade contemporânea apresentava novas peculiaridades.

A Constituição Federal promulgada no ano de 1988, foi um marco para o processo coletivo pois bipartiu o processo civil brasileiro em individual e coletivo prevendo em seu regramento os direitos transindividuais, para posteriormente com a emenda constitucional $\mathrm{n}^{\circ} .45$, estabelecer a ideia de aceso a ordem jurídica justa, portanto resolução de conflitos em tempo razoável como prevê o art. $5^{\circ}$ LXXVIII da CF, em correspondência com o art. $2^{\circ}$ do Código de Processo Civil, portanto avançando no conceito de inclusão jurisdicional.

Além disso, regulamentou o direito das partes a assistência judiciária gratuita integral, na forma do art. $5^{\circ}$ LXXIV e a criação de juizados especiais cíveis e federais, posteriormente formalizados pelas leis 9099/95 e 10.259/2001, em que pese ter tratado em seu art. $5^{\circ}$ XXXV do acesso à justiça de forma genérica (Carvalho, 2016, p. 143).

Outras leis posteriormente foram sendo editadas a fortalecer o Sistema Processual Coletivo, do qual podemos citar, a tutela de interesses transindividuais de pessoas portadoras de deficiência (lei 7.853 de 24.10.1989, a Lei Protetiva dos Investidores do Mercado de Valores Mobiliários (Lei7.913 de 07 de dezembro de 1989), o Código de Defesa do Consumidor 
(Lei 8.078 de 11.09.1990), o Estatuto da Criança e do Adolescente (Lei 8.069 de 11 de setembro de 1990), a Lei da Probidade da Administração Pública (Lei8.429/92 de 02.06.1992), , e a Lei de Prevenção e Repressão às Infrações contra a Ordem Econômica - Antitruste (Lei8.884 de 11 de junho de 1994), e dos interesses das pessoas idosas (lei 10.741 de 01.10.2003, etc., com características peculiares, com objetivo de atender conflitos sociais, envolvendo um grupo ou categoria de pessoas (conflitos de massa), com mecanismos específicos, em ações com alto grau de dificuldade (Gomes Jr., et.al., 2019, p. 2).

Porém, a legislação ainda é muito restrita quanto a este acesso pelo judiciário nas ações coletivas, em que pese a legitimação ampliada prevista constitucionalmente e pelo Código de Defesa do Consumidor que expressamente concebeu a determinados entes iniciativa para certas ações coletivas, como é o caso do Ministério Público, até porque a ideia é permitir a tutela coletiva dos direitos individuais ligados entre si pelo vínculo da homogeneidade (Grinover, et al, 2014, p. 709).

É evidente, que obstar ou criar entraves ao amplo emprego do processo coletivo quando discutidos direitos transindividuais (direitos difusos e coletivos) implica obstar o acesso à justiça, posto que não há como tutelá-los individualmente com a utilização dos instrumentos do processo civil tradicional, posto que o substrato jurídico-material indivisível, de caráter coletivo nos impõe tal constatação (Talamini, 2015, p. 2).

Santos (2003, p. 61-62) afirma que o processo coletivo surgiu para garantir o atendimento as reinvindicações de uma sociedade de massa, que não se configura apenas pela quantidade de indivíduos que a compõe, mas pela supremacia de sua uniformidade social, no qual todos os componentes do grupo devem ser tratados de forma igual nos aspectos formais e materiais. Prossegue o autor demonstrando suas características:

a) ausência de organização social; presença de uma agregação de indivíduos que, embora separados, desligados ou anônimos, possuem homogeneidade em relação a determinados comportamentos ou situações nas quais se encontram; b) os comportamentos são não-organizados, não-estruturados, não-coordenados; c) caracteriza-se pelo comportamento de massas, isto é, nele as pessoas agem individualmente, mas na mesma direção e com estímulos e condições idênticas; d) não se manifestam por meio de um grupo, mas individualmente de forma uniforme; e) massa não consiste num grupo, não pode interagir, mas pode ser levemente identificada pela uniformidade; há uma fluidez da pessoalidade -mais precisamente nas sociedades primitivas - para a impessoalidade, particularidade esta das sociedades modernas.

É importante frisar, portanto, que o ponto de partida do sistema de processos coletivos, no Brasil, foi dar tutela a direitos que, naquele dado momento histórico (segunda metade do século XXI), não poderiam ser enquadrados nos mecanismos e instrumentos processuais positivados. Entretanto essa "urgência" em garantir meios para efetivação destes novos direitos, sem uma análise pormenorizada de conceitos fundamentais sobre a matéria a alicerça-la como novidade na legislação, traz problemas quanto ao desenvolvimento da matéria há décadas, pela imprecisão, por exemplo em definir quem são os titulares dos direitos transindividuais? Os estudiosos atribuem essa titularidade, à "sociedade", a "grupos" ou à "coletividade", expressões genéricas e que servem muitas vezes apenas para dar uma aparência de efetivação dos direitos a esta categoria, que em muitos casos até desconhecem ou discordam da tutela eventualmente deferida na relação jurídica formada (Vitoreli, 2019, p. 27).

Isso se deve também ao fato de que a tutela coletiva não foi bem compreendida sendo que a aprovação do Código de Processo Coletivo, ainda no ano de 2010, teria trazido com mais rapidez a clareza, proteção e importância que este instituto merece até porque neste constava a criação de varas especializadas e prioridade processual em ações desta natureza, conforme disposto em seu Anteprojeto no art. 10: "o juiz deve dar prioridade ao processamento da ação coletiva salvo quando não haja manifesto interesse social evidenciado pela dimensão do dano ou pela relevância do bem jurídico a ser protegido" (Carvalho, 2006, p. 205).

Grinover (1984, p. 37), já dizia "que o processualista tenha a coragem intelectual de admitir que hoje aflora no processo situações diversas daquela que constituíam o suporte dos institutos tradicionais. A tradição doutrinária não pode 
significar um obstáculo para repensar institutos", de forma que o surgimento de novos tipos de demandas tornavam imprescindíveis, o estabelecimento de as molda-las a novas disposições legais.

José Carlos Barbosa Moreira (1988, p. 189) diz que a partir da Constituição Federal vigente as "ações coletivas assumiram dimensão jamais vista no Direito Brasileiro. Isso se deve por evidente ao reconhecimento pelo Estado Democrático de Direito dos direitos transindividuais e da importância das formações sociais para a vida democrática nacional"

Assim, faz -se necessário entender os mecanismos para efetivação das tutelas coletivas, e a relação entre os legitimados e detentores do direito, já que ao defender no processo o direito de uma coletividade, uma das pessoas lesadas, um ente ou pessoa pública, estará sendo potencializado o acesso à justiça. Entretanto, existem problemas que devem ser postos em discussão, pois nem todos os titulares de direito poderão se manifestar, e como poderíamos garantir que a representação do legitimado na instrução processual está em conformidade com o que pleiteia o detentor do direito se não há prévia comunicação entre eles? (Vitorelli, 2019, p. 13).

O processo coletivo é importantíssimo para garantir o acesso à justiça, porque mostra-se como um procedimento adequado e eficiente, para "quebrar barreiras", mesmo quando esgotada as possibilidades de ação individual. A tutela do direito, ora desrespeitado que lese uma infinidade de pessoas pode ser resolvida conjuntamente com menor dispêndio de dinheiro e de tempo com uma única ação coletiva (Mendes, et.al., 2018, p. 238).

\subsection{Ações Coletivas: conceito, requisitos e relevância}

Com intuito de adentrarmos na discussão sobre os desafios do direito coletivo, como ciência autônoma do direito na resolução de conflitos de massa, faz-se necessário inicialmente conceituar a própria ação coletiva, sendo que o tema demanda grandes discussões doutrinárias em que pese ter se firmado no Brasil a mais de cinquenta anos, com a publicação da lei de Ação Popular (lei 4.717/65) tendo como marco histórico que a consolida a promulgação da Lei de Ação Civil Pública (Lei 7347/85).

Luciano Velasque Rocha (2002, p. 269), definiu ação coletiva há 17 anos atrás partindo da diferenciação da legitimidade ativa e da coisa julgada, com o processo civil tradicional, asseverando que a exata definição passava pela análise da possibilidade de legitimados pleitearem direitos alheios em juízo, e pela extensão da coisa julgada além das partes processuais.

De forma bem simples poderíamos definir ação coletiva como sendo uma demanda que origina um processo coletivo, que pode ser ativo ou passivo. Esse processo coletivo deve ter caráter litigioso e coletivo, sendo que uma das partes da ação deve ser coletiva, ou seja, se constituir por grupo, categoria ou classe (Didier Jr., 2016, p. 32).

Em Contraponto Antônio Gidi (1995, p. 160), diz que para definição de uma ação coletiva faz-se necessário três requisitos, quais sejam legitimidade, o objeto do processo e a coisa julgada.

Para Luiz Manoel Gomes Jr e Luana Pedrosa de Figueiredo Cruz (2019, pag. 292), a ação coletiva possui 03 (três) requisitos, quais sejam um, sistema de legitimidade diferenciada, o que significa um rompimento com as ideias clássicas de legitimidade ordinária e extraordinária, sendo que a exata noção de legitimidade partiria de uma previsão legal.

No mesmo sentido Thereza Arruda Alvim (1996, p. 118), defende a autonomia e exclusividade da tutela coletiva, devendo esta ação ser vista como uma novidade, que difere e, portanto, não se enquadra aos conceitos de legitimidade até então positivados, pois trata-se de uma espécie de legitimação própria e autônoma.

Além disso, a ação coletiva deve possuir um regime especial da coisa julgada, no qual os efeitos que dela irradiam tem caráter ampliativo (além das partes processuais) com aplicação secundum eventum probationis (prova dos fatos) sendo seu objeto um ou mais direitos coletivos, posto que a ação deve se concentrar na defesa de direitos coletivos, ainda que de forma acidental como no caso dos direitos individuais homogêneos (Gomes, 2019, p. 292). 
Ora, ao tratamos de direitos coletivos, não nos parece correto, por obviedade buscar o resguardo do direito de um único indivíduo, mas também não é apenas a existência de uma pluralidade de indivíduos, ora titulares de pretensões homogêneas, que justificarão por si só o uso das ações coletivas.

Na visão de Eduardo Talamini (2015, p. 339), é preciso que além da tutela do direito de múltiplos indivíduos, ainda haja uma possível lesão ou ameaça que tenha o condão de atingir um número significativo de indivíduos, seja ele indeterminado ou não, desde que demonstrado cabalmente a potencialidade de lhes causar lesão. Prossegue o autor que apenas nestas circunstâncias há configuração do interesse difuso (conflito de massa), gerando a necessidade da tutela coletiva. Posteriormente, já no curso do processo, durante ou finda a instrução processual, já no momento de habilitação de interessados para a liquidação e execução individuais, é possível se deparar com a diminuição ou até inexistência dos indivíduos envolvidos, mas tal situação não desconfigura a ação coletiva pois a revelação da tutela coletiva se revela no resguardo e proteção do interesse difuso, no sentido de coibir condutas potencialmente lesivas em proporções significativas.

O Sistema Processual Coletivo ainda trouxe várias espécies de instrumentos para a tutela coletiva, como a Ação Civil Pública, a Ação Popular, o Mandado de Segurança Coletivo, a Ação de Improbidade Administrativa, no âmbito eleitoral a Ação de Impugnação de Mandato Eletivo, e até mesmo a ação penal condenatória (Didier Jr., et. al., 2016, p. 33).

O processo coletivo é tão importante que vários instrumentos processuais utilizados no processo civil individual, surgiram através deste, como é o caso de clausulas gerais, antecipação de tutela, e provimentos de natureza mandamental e executiva (Carvalho, 2016, p. 205)

\subsection{Desafios de conceituação: natureza jurídica, titularidade e coisa julgada no direito coletivo}

No Código de Processo Civil de 1973 em seu art. $6^{\circ}$ existia uma previsão que apenas os detentores do direito teriam legitimidade para pretendê-los em juízo. Essa disposição possuía correspondência com a Constituição Federal de 1967.

Entretanto a Constituição Federal a partir do ano de 1988 trouxe à figura da representação coletiva potencializando o acesso à justiça, por meio da tutela dos direitos transindividuais, posto que a partir desse momento o titular do direito material não precisa ser necessariamente o titular do direito de ação, de forma que entes poderiam representar grupos ou classes de indivíduos (Silva, p. 260).

O Código de Defesa do Consumidor potencializou a legitimação para ações coletivas colaborando com a previsão constitucional de 1988, sendo que os legitimados podem ser o próprio cidadão (ação popular), órgãos públicos (Ação Civil Pública) e até partidos políticos, associações civis e sindicatos (Mendes, p. 245).

Desde então inúmeros debates na doutrina, sobre qual a natureza jurídica do legitimado no processo coletivo se intensificaram, sendo que para Freddie Didier Jr e Hermes Zaneti Jr (2016, p. 177), trata-se de legitimidade extraordinária, posto que o titular do direito material será um grupo, ou uma coletividade enquanto que o direito de ação é promovido por ente que não possui relação com o direito ora discutido.

Acelino Rodrigues Carvalho (2003, p.275) defende que a forma como é posta a definição em ordinária e extraordinária pela doutrina sob o enfoque de coincidência entre o titular do direito e o titular da ação é equivocado, sendo que ordinária é quando algo ocorre sob determinadas circunstâncias normais, comuns e corriqueiras e extraordinária quando considerada, anormal, eventual, de forma que a legitimação nas ações coletivas deve ser considerada ordinária porque, deve ser algo comum a organização de comunidades para postular em juízo seus direitos a saúde, educação, sendo certo que isto ocorrerá sob a modalidade de substituição processual.

Entretanto, as ações coletivas são inovações legislativas, uma espécie de terceiro gênero, que não se afigura no binômio legitimação ordinária/extraordinária. Ora, como defender ser ordinária se há um direito coletivo no qual nem sempre o autor da ação será detentor do direito material? Por outro lado, ao enquadrar as ações coletivas como de legitimação 
extraordinária limitar-se-ia o conceito, não abrangendo todas as situações, vez que o legitimado coletivo defende direito próprio, ainda que haja similitude com o direito da comunidade/coletividade (Gomes Jr., et.al., p. 462).

A mesma senda trilha a substituição processual, quanto a sua inaplicabilidade no processo coletivo, pois tal instituto deve ser definido como aquele no qual o autor da ação é titular do direito invocado, sendo que a decisão pode afetar terceiros que não participam da relação jurídica processual. Ocorre que o substituído não pode ser parte, mas em uma das espécies de ação coletiva, qual seja ação popular em havendo habilitação de outro cidadão inadaptável estará o procedimento. Soma-se a isso o fato de que a decisão gera reflexos ao substituído, e que a sentença de improcedência, não impede a tutela individual do direito (Gomes Jr., et. al., 2013, p.462).

Se a legitimidade causa discussões acaloradas do ponto de vista doutrinário, melhor sorte, não há quanto a titularidade do direito material. Ora, se na ação coletiva os titulares do direito são a coletividade (grupo, associação, classe, etc.), estas precisam ser bem definidas, pois, se levarmos em consideração a ideia de legitimação extraordinária, o autor da ação deve compreender quais as pretensões destes indivíduos, a fim de pleitear a tutela adequada, que não pode ser abstrata e deve retratar a realidade vivida por estes indivíduos. O problema é que nas ações transindividuais temos exatamente a situação oposta, na qual os titulares do direito são indeterminados. Por esta razão apesar de entender que o legislador pretendeu com as ações coletivas ampliar a proteção ao máximo de indivíduos, é arriscado agir em nome de pessoas sem conhecer seus reais propósitos sob pena do resultado da demanda ser contrário ao interesse de quem se buscou proteger (Vitorelli, 2019, p. 11).

Em que pese as ponderações postas sob discussão, o Brasil adota uma legitimação plúrima -com vários legitimados- e mista, no sentido de ter sua composição baseada em entes da sociedade civil como associações, sindicatos, partidos políticos e órgãos do poder público, cito, Ministério Público e Defensoria Pública (Didier Jr., et. al., 2016, p. 182).

Segundo Edilson Vitorelli (2019, p. 13), ainda podemos ter dificuldades em estabelecer quem decidirá a melhor forma de solução do litigio em caso de serem possíveis várias formas de resolvê-lo ou minorar suas consequências, classificando as pretensões das ações coletivas em simples e complexas. A primeira se refere a pretensão unívoca e de fácil compreensão, já na segunda nem a pretensão, tampouco a tutela é unívoca, como é o caso de conflitos sócioambientais, com múltiplos contornos, na qual fica difícil estabelecer no caso in concreto qual das formas disponibilizadas possibilitarão a prevenção ou reparação do dano coletivo, pelo qual o autor indaga a quem caberá a escolha entre uma das formas de agir para evitar ou minorar o dano. Seria esta decisão do legitimado coletivo?

Além dessa questão chamada pelo autor de complexidade, ainda há o problema da conflituosidade que seria basicamente os titulares do direito (conhecidos) divergirem entre si sobre qual a tutela adequada, e neste caso pairaria a dúvida sobre como agir. Teria o juiz possibilidade de adequar o feito a sua forma de pensar ou o legitimado decidir sobre o que lhe parecerá à melhor solução? (Vitorelli, 2019, p. 14).

Antônio Gidi (1995, p. 26), traz outro conceito tortuoso, qual seja, que as ações coletivas podem trazer prejuízo as partes, que estão ausentes do processo, justificando que se a ação não for julgada por insuficiência de provas não poderá ser reproposta, e o direito discutido será fulminado. Mesmo a sentença de procedência poderia ser vista por esse prisma como deflagradora de prejuízo, já que uma vez reconhecido o direito sobre um prisma, as outras possibilidades que com ela são contraditórias, restar-se-ão excluídas.

José Carlos Barbosa Moreira (1984, p. 190), retrata a questão da ação de procedência ter o condão de gerar prejuízos, dizendo que as peculiaridades que rejam um caso concreto, poderão dar ensejo a variadas formas de reparação do dano, que se exercidas de determinada forma excluirão sua prestação de outra, citando o exemplo de uma empresa de saneamento de esgoto que foi condenada a implementar o sistema de esgoto em certo prazo. Ora, se o juiz decidir este "certo prazo" com base no que o legitimado requereu impedirá que outros indivíduos ausentes no processo o peçam posteriormente em prazo menor. No mesmo sentido, a decisão que fixa a forma de "implementação de esgoto", pode não ser a mais adequada aos anseios daquele 
grupo, ou ainda que prestada não repare eventuais prejuízos que buscou-se coibir, mesmo assim o manto da coisa julgada impede que a ação seja reproposta e rediscuta-se por outros indivíduos daquela coletividade forma diversa de implementação do esgoto.

Eurico Zecchin Maiolino (2018, p. 62), diz que o "direito brasileiro não condicionou a extensão subjetiva da coisa julgada à representação adequada”, mas enumerou seus legitimados no Código de Defesa do Consumidor (art. 82 da lei 8078/90), impedindo que em caso de improcedência do pedido os terceiros ausentes nos autos sejam maculados em suas esferas individuais, de forma que a coisa julgada seria secundum eventum litis, ou seja somente terá validade para beneficiar, sendo assim in utilibus.

Sobre este prisma de representatividade adequada, é a lição de Aluísio Gonçalves de Castro Mendes (2012, p. 244), que em nossa legislação a representação é ope legis e não ope judicis, de forma que foi estabelecido legitimados (Ministério Público, a Defensoria Pública, a União, entes federados, etc.), no que difere estruturalmente do modelo norte-americano, no qual o juiz afere se há representatividade adequada levando em consideração aspectos diversos como "histórico de atuação, a capacidade financeira do advogado etc".

Com a vigência do Novo Código de Processo Civil, havia uma tentativa de aproximar os conceitos individuais e coletivos, tornando possível sua coexistência de forma integrada, com o art. 333 que previa a possibilidade de conversão da ação individual em ação coletiva que foi vetado.

Mas talvez isso sequer fosse necessário, ou até impossível, posto que na visão de Edilson Vitorelli (2019, p.17) é um erro tentar separar mecanicamente "o indivíduo da sociedade", ou seja os direitos coletivos dos individuais, porque ainda que a lesão atinja a todos, dificilmente o será com a mesma intensidade, e reciprocamente os direitos individuais repercutem no grupo que condiciona o primeiro, haja vista a própria configuração de sua estrutura social.

Ainda nos deparamos com a discussão sobre as chamadas ações coletivas passivas, que são reconhecidas e definidas por Freddie Didier Junior e Hermes Zaneti Jr (2016, p. 457-458), quando "um agrupamento humano for colocado como sujeito passivo de uma relação jurídica afirmada na petição inicial", ou seja para sua configuração deve haver ajuizamento de uma ação coletiva contra uma coletividade, proposta contra um "representante adequado, presente o interesse social, sendo que a coletividade será sujeita de um dever ou estado de sujeição".

Em sentido contrário Edilson Vitorelli (2018, p. 311), diz que as ações coletivas passivas não existem no Brasil, e só causariam injustiças se existissem, visto que onde surgiram (Estados Unidos), são raras. Prossegue o autor, dissertando que não há sequer uma definição precisa de "representatividade adequada" e que essa imprecisão geraria utilidade mínima em favor da coletividade, mas em contraponto favoreceria o direito individual, com alta possibilidade de prejudicar grupos sociais principalmente os vulneráveis, com uma coisa julgada perniciosa aos ausentes que não teriam sequer conhecimento da decisão, e possibilidade de lesão direta a seu patrimônio pessoal.

Luis Manoel Gomes Junior e Luana Pedrosa de Figueiredo Cruz (2019, p. 300-301)) asseveram que apesar dos problemas conceituais envolvendo a ideia de representatividade adequada e abrangência da coisa julgada, as ações coletivas passivas existem no direito brasileiro, e tem sua utilidade, servindo como instrumento de controle.

No mesmo sentido Aluísio Gonçalves de Castro Mendes (2012, p. 252), diz que as ações coletivas foram de fato inicialmente criadas para defesa desses direitos no âmbito do pólo passivo, como no caso da ação popular, mas na Constituição Federal em seu art. $8^{\circ}$ inciso III, ao tratar de sindicatos o legislador, não impôs limitações a atuação no polo ativo ou passivo. Além disso é possível justificar a utilização das ações coletivas passivas pelo princípio de acesso à justiça/ inafastabilidade da jurisdição (art. $5^{\circ}$ XXXV CF), e em ações incidentes ou derivadas (ações rescisórias, reconvenções, embargos de terceiro, etc.), havendo portanto um grupo de ações coletivas passivas que se originam da própria ação coletiva, sendo que apesar de não serem tão comuns essa modalidade é presente no direito brasileiro. 
Por fim ainda destacamos a questão da imprecisão conceitual de que os direitos transindividuais são de "todos" e que "todos" serão lesados em caso de dano ao bem tutelado. Ora essa ideia mascara muitas vezes a impossibilidade de definir de forma objetiva quem é o titular do direito, até porque ainda que a lesão diga respeito a poluição ambiental de determinada cidade, é notório que haverá prejuízo e portanto eventual lesão ao limitado número de moradores da localidade, sob pena de interpretação diversa levar a conclusão que todos os indivíduos do planeta são lesados em causas que envolvam danos ao meio ambiente (Vitorelli, 2019, p. 28).

Essa ideia, porém, de estender os efeitos dos danos a coletividade em escala global, erigindo o sistema coletivo a um patamar transnacional, possui adeptos, sendo defendido por Aluísio Gonçalves de Castro Mendes e Larissa Clare Pochmann da Silva (2018, p. 241), que argumentam que os danos de massa não respeitam fronteiras entre estados ou barreiras geográficas pois "um dano ambiental, um produto defeituoso, uma prática fraudulenta em determinada ação na bolsa de valores, em todos eles são apenas alguns exemplos que podem se estender para uma dimensão bem além das fronteiras de um país [...]”.

No mesmo sentido é a visão de Michelle Taruffo (2012, p. 26), para quem a administração da justiça e o resguardo de direitos, no mundo globalizado não pode sofrer limitações de soberania de Estados, lesões de grande repercussão a uma infinidade de indivíduos deveriam ser tutelado por um "sistema transnacional de proteção ao patrimônio transindividual da humanidade", que hoje é inexistente.

Em agosto deste ano, foi noticiado que ocorreu um vazamento de petróleo cru no oceano, com potencial devastador ao meio ambiente. O jornal Correio do Povo no dia 08 de novembro de 2019, trouxe dados que o óleo derramado no mar, atingiu o Brasil por quase 2 (dois) mil $\mathrm{Km}$ em sua costa, se estendendo por 409 praias de vários estados do pais, esse é o típico caso que um tribunal internacional poderia atuar de acordo em esta visão de um "sistema transnacional de proteção a direitos transindividuais". Como não há, cabe ao Estado-País, tutelar a parcela desse patrimônio atingido que se encontrar em seu território.

Assim, é necessário grande responsabilidade ao tratarmos de um tema tão volúvel quanto ações coletivas, pois como já ressaltado não é um tema o qual se esta habituado e que possui uma amplitude colossal, regulando uma faceta diferente da realidade, constituindo portanto um novo processo civil, de forma que apenas os operadores do direito que abandonarem os padrões tradicionais do processo serão capazes de entendê-lo, recepcioná-lo e sobretudo reconhecê-lo como indispensável para implementar as necessidades do nosso tempo, em que os grupos, classes, massas definitivamente passaram a organizar-se, e pleitearem seus direitos (Alvim, et. al, 2014, p. 11).

\subsection{Tentativas de estabelecer um regramento específico}

Após diversas codificações esparsas, que foram criadas com intervalos de décadas entre elas (por exemplo o interregno de tempo entre a promulgação da lei de ação popular e a lei de ação civil pública é de 20 anos), foi apresentado o Projeto de Lei sob n. 5.139/2009 junto a Câmara dos Deputados, autorizado pelo Ministério da Justiça pela Portaria 2.481/2008 que criou uma Comissão Especial com a finalidade de apresentar uma proposta de readequação e modernização da tutela coletiva propondo uma normatização do sistema coletivo, com o condão de substituir a Lei de Ação Civil Pública, e ampliar o acesso a justiça, visto que compreendeu-se que esta espécie de conflito carecia de normas específicas.

Este projeto de lei, tinha por objetivo, encerrar ou minorar eventuais dúvidas relativas a competência, legitimidade, coisa julgada, etc., inerentes ao direito coletivo, entraves que dificultam a prestação jurisdicional e o acesso à justiça nestas demandas de massa, que não raras vezes são resolvidas pela aplicação analógica de regras de diferentes codificações. Esta nova codificação seria o início de uma pretendida coerência ao sistema coletivo com a padronização do processamento e aplicabilidade do direito apropriado (Gomes Jr., et. al., 2009, p. 176-177).

Interessante ressaltar a densidade deste anteprojeto, seja pela sua extensão (contava com 71 (setenta e um artigos), ou 
por seu conteúdo, já que englobava os direitos coletivos de várias leis (art. $1^{\circ}$ ), estabelecia uma parte principiológica, como vetores de intepretação das normas que viessem a seguir (art. $3^{\circ}$ ), pressupostos e condições da ação $\left(\operatorname{art.} 4^{\circ}\right.$ ), estendia o rol dos legitimados da Lei de Ação Civil Pública (art. $6^{\circ}$ ), explicitava todo o procedimento e peculiaridades do tipo (art. 10 a 21), demonstrava as técnicas a serem aplicadas e a forma de processamento recursal (art. 22 a 39), liquidação e execução (art. 40 a 46), tratando a seguir do Termo de Ajustamento de Conduta e do Cadastro das Ações coletivas como forma de lhe dar ampla publicidade (art. 47 a 54), despesas e honorários advocatícios (art. 55 a 56), possibilidade extrajudicial de reparação de danos (art. 57 a 61), com disposições finais, englobando preferência das ações coletivas sobre individuais, forma de homologação de sentença estrangeira, aplicação subsidiária do CPC/73, etc. (art. 62 a 71).

As ideias principais deste projeto, eram a criação de um sistema único coletivo, que normatizasse todas as ações coletivas (seja relativa a idosos, criança e adolescente, pessoas portadoras de deficiência, entre outras) estabelecendo regra gerais, sem desprezar leis específicas que permaneceriam vigentes (ex: lei de improbidade administrativa) criando uma espécie de microssistema, ampliar o rol dos direitos coletivos da Ação Civil Pública, com a criação de uma legitimação processual coletiva e ampliação do rol de legitimados (OAB, Defensoria Pública e partidos políticos), com estabelecimento da competência fixada pelo local do ato ilícito (relembre-se que a LACP utilizava o termo "dano"), e coisa julgada "secundum eventum probationis", com exceção das ações que envolvessem direitos individuais homogêneos no qual o regime seria "pro et contra", impedindo novas ações individuais com o mesmo objeto. Além disso criava novas regras de distribuição do ônus da prova, a ser aplicada aquele que detinham de melhor conhecimento técnico ou informações, e um sistema extrajudicial de prevenção e reparação de danos. Por fim previa a criação de um fundo no qual se concentraria o montante resultante de condenações em ações coletivas que teriam sua destinação deliberada pela própria sociedade (Gomes Jr., Favreto, 2009, p. 179-189).

Tal projeto de lei, foi rejeitado em 17 de março de 2010, e desde então, por mais de 10 (dez) anos, não havia uma mobilização pela criação de um sistema coletivo abarcando estas ideias pelo que pareceu-se que neste ponto ficaríamos mais algumas décadas sem o regramento da matéria, dificultando o acesso à justiça de milhares de pessoas que tem apenas nas ações coletivas a forma propicia de manifestarem suas pretensões.

Entretanto, no dia 02 de setembro de 2020, foi entregue na Câmara de Deputados, uma proposta de criação de uma lei de ação coletiva, realizada por um grupo de juristas, autorizado por meio da Portaria 152/19, assinada pelo presidente do Conselho Nacional de Justiça, a época, ministro Dias Toffoli, com 35 (trinta e cinco) artigos, cuja coordenadora é a Ministra do Superior Tribunal de Justiça Maria Isabel Diniz Galotti, que traz distinções em relação ao projeto apresentado outrora, principalmente pela sua simplicidade.

As principais propostas são o estabelecimento de um sistema processual coletivo único, com prioridade no Processamento e Afetação (art. $2^{\circ}$ ), estendendo o rol de legitimados da Lei de Ação Civil Pública ao possibilitar o ajuizamento por entidades e órgãos ainda que sem personalidade jurídica, e associações, sendo que no primeiro caso exige destinação específica e no segundo representatividade adequada (explica no art. $4^{\circ}$ ), com autorização estatutária ou assemblear. Confere amplo acesso à justiça, possibilitando a defesa dos direitos coletivos com qualquer tipo de ação (art. $5^{\circ}$ ), delimita o alcance do pedido que deve ser expresso quanto a causa petendi (art. $6^{\circ}$ ), em caso da existência de ações individuais, insere que tal comportamento não induz litispendência, torna possível a ampliação do prazo de contestação, e estabelece a possibilidade da realização de negócios jurídicos processuais (art.12).

Além disso, define regras de competência que ao contrário do projeto anterior não será do local do ato ilícito, mas sim da capital no qual ocorreu o dano, e em varas especializadas, pelo que interpreta-se serão criadas (art. 13) impondo ainda que os pretensos legitimados estejam cadastrados no Conselho Nacional de Justiça, como forma de demonstrar seu interesse processual (art. 14). Em alguns pontos tenta tornar o processamento mais célere ao possibilitar que na sentença seja utilizado a 
motivação do inquérito civil, se neste houve oportunização do contraditório (art. 19), possibilidade de inversão do ônus da prova a tornar mais célere a sua colheita (art. 20), inclusive se necessário com a inversão de seu custeio (art. 21), sendo aceito provas por amostragem (art. 22), com especificação da destinação dos valores de multa para um fundo ou para parte conforme tratarem-se de direitos difusos, coletivos ou individuais homogêneos (art. 23).

Por fim a coisa julgada adotada parece ser "pro et contra" (Art. 25), o ajuizamento da ação coletiva não interrompe a prescrição para ações individuais, e nem a suspende (par. $4^{\circ}$ e $5^{\circ}$ ), não sendo possível nova ação coletiva com o mesmo objeto. Se ocorrer será apensa a primeira ação, o que fará com que a instrução já iniciada prossiga e gere efeitos a estes legitimados (art. 26), sem prejuízo de a qualquer tempo estas questões serem resolvidas por acordo ou Termo de Ajustamento de Conduta (art. 28), deixando o regramento recursal, custas, sucumbência, a cargo das disposições do Código de Processo Civil, a qual preceitua de aplicação subsidiária (art. 31 a 33).

Assim, resta claro que esta nova tentativa de codificação possui redação mais simples e direta que a anterior, carecendo em alguns pontos de uma melhor explicitação, pois não esclarece e soluciona questões fundamentais dos direitos coletivos, pelo que pode não gerar o efeito pretendido de disciplinar o sistema coletivo, principalmente porque certamente sofrerá desgastes em sua tramitação no legislativo. Por outro lado, apresenta avanços, a legislação vigente, principalmente porque possui similitude com o regramento do Código de Processo Civil, se utilizando de mecanismos que nos últimos anos já tornaram as ações individuais mais céleres, como é o caso da distribuição dinâmica do ônus da prova, negócios jurídicos processuais, possibilidade ampla de acordo, etc.

\section{Considerações Finais}

O Sistema Processual Coletivo brasileiro, se desenvolve de forma lenta e gradual, já tendo impactado em larga escala na potencialização do acesso a justiça do jurisdicionado que isoladamente, fazendo uso de técnicas legislativas voltadas aos processos individuais, teria seu direito cerceado.

Entretanto, a distância cronológica entre as codificações a reger os processos coletivos e a própria dificuldade de entendimento dos conceitos estruturais destas ações, impedem a emancipação desta ciência como autônoma e porque não dizer a própria efetivação dos direitos dos jurisdicionados que necessitam dos institutos coletivos para evitar ou reparar danos não regidos pelo processo civil tradicional.

Ora, o dinamismo da sociedade, caracterizada pela complexidade cada vez mais aparente dos conflitos na ordem jurídica e social, gera uma propensão a danos em massa, os quais somente com as concepções estruturadas do sistema coletivo conseguiremos sobrepujá-las ou ao menos atenuá-las.

Como consequência, o presente trabalho se propõe a trazer uma reflexão sobre o processo coletivo enquanto instrumento capaz de assegurar a concretização de direitos fundamentais em larga escala, a uma infinidade de indivíduos, e de forma rápida e efetiva, já que a sociedade moderna, despertou sua consciência e exige direitos a educação, saúde, moradia, meio ambiente saudável, etc., e a existência de uma ciência autônoma do direito consolidada, que proteja os indivíduos contra lesões massificadas, é requisito fundamental para a efetivação de um estado democrático de direito, em sintonia com as necessidades da nossa sociedade atual.

Ademais, as ações coletivas garantem o acesso à justiça substancial e não apenas meramente formal, concedendo ao jurisdicionados celeridade e economia judicial e processual. Além disso, este acesso à justiça é identificado com obediência aos primados de isonomia e segurança jurídica já que ao tratar em único processo de causa que afeta centenas, milhares de pessoas haverá decisão uniforme a todos os envolvidos.

Outrossim, necessário se faz entender os conceitos estruturais deste novo tipo de ação e suas peculiaridades, visto que inconciliável o tratamento destas ações aos procedimentos e mecanismos das demandas individuais. Neste sentido foi a 
tentativa de codificação no ano de 2009, que restou frustrada, apesar de apresentar de uma forma bem completa, estas peculiaridades, inclusive estabelecendo como seria a legitimidade, competência, destinação de verbas e seu processamento em primeiro e segundo grau.

$\mathrm{O}$ atual anteprojeto mostra-se comedido, menos complexo, talvez como forma de conseguir de forma mais fácil sua aprovação, é em muitos pontos parecido com o anterior, mas sem a finesse e profundidade, se aproveitando de vários mecanismos no Código de Processo Civil vigente, inexistente a época da primeira proposta, demonstrando um alto grau de eficiência, deixando para a doutrina suas minucias, de forma que neste ponto poderá trazer um grande avanço ao sistema de direito coletivo.

Entretanto a falta de robustez do anteprojeto, pode gerar os mesmos problemas de outrora com o predomínio de aplicação de normas de direito individual as ações coletivas, o que já se mostrou pela experiência inapropriado. Neste sentido a pretensa lei se escora no Código de Processo Civil, prevendo sua aplicação direta (esfera recursal, sistema de custas e honorários, etc.), e subsidiária nas ações coletivas.

Por outro lado deixa de tratar de pontos polêmicos como a natureza da legitimidade das ações coletivas (ordinária, extraordinária, substituição processual), e não esclarece sobre outros (sistema de representatividade adequada, alteração do regime de coisa julgada que era segundo art. 103 par. $2^{\circ}$ e $3^{\circ}$ do CDC secundum eventum litis e agora propõem-se como pro et contra, etc.), ao que parece aguardando que a doutrina esclareça tais lacunas legislativas.

Por fim, aguardamos que tal anteprojeto, a partir de discussões nas casas legislativas e perante a sociedade via audiências públicas, possa ser robustecido, sob pena de ter caráter paliativo, e perdermos novamente a oportunidade (fato que desde a promulgação da lei de Ação Civil Pública no ano de 1985, já perdura por quase quatro décadas) de concretizar direitos fundamentais de acesso à justiça, duração razoável do processo, segurança jurídica e eficiência.

\section{Referências}

Alvim, T. (1996). O Direito Processual de Estar em Juízo. Editora Revista dos tribunais.

Alvim, T. A., Benjamim, A. H., Grinover, A. P. \& Vigoriti, V. (2014) Processo Coletivo. Do Surgimento a Realidade. Editora Revista dos tribunais.

Cappelletti, M., Garth, B. (1988) Acesso à Justiça. Tradução e revisão de Ellen Gracie Northfleet. Sergio Antonio Fabris Editor, 1988.

Carvalho, A. R. (2006) Substituição Processual no Processo Coletivo. Um Instrumento de Efetivação do Estado Democrático de Direito. São Paulo Editora Pilares, 2006.

Didier Jr., F., \& Zaneti Jr., H. (2016) Curso de Direito Processual Civil-Processo Coletivo. JusPodivm.

Dinamarco, C. R. (1999). Instituições de Direito Processual Civil. Malheiros.

Fonseca, J. P. da (2020). Ações Coletivas: evolução e desafios para um perspectiva transformadora da jurisdição à luz do princípio do acesso à justiça. Cambi, E.A.S.; Chueiri, M.F.; Gomes Júnior, L.M. (Orgs). Processo e Direitos Fundamentais. p. 105-126. https://pos.unipar.br/files/publ icao_academica/f9e7846096b78f21aed1929d35d1bdee.pdf

Grinover, A. P. (coord.). (1984). A tutela dos interesses difusos: doutrina, jurisprudência e trabalhos forenses. São Paulo: Max Limonad.

Gomes Júnior, L. M., \& Cruz, L. P. de F. (2019, janeiro) Ações Coletivas Passivas- Um diálogo com a doutrina-Primeira Parte. Revista de Processo. DTR 2018 22815. São Paulo: Revista dos Tribunais. 287, 291 - 305.

Gomes Júnior, L.M., \& Chueiri, M. F. (2013, julho) Sistema Coletivo: Porque não há substituição processual nas ações coletivas. Revista de Processo, DTR\2013।3815. São Paulo: Revista dos Tribunais. 221, $461-472$.

Gomes Júnior, L. M., \& Favreto, R. (2019, outubro). Anotações sobre o Projeto da Nova Lei da Ação Civil Pública: Principais Inovações. Revista de Processo, DTR 2009\884. São Paulo: Revista dos Tribunais. 176, $174-194$.

Gidi, A. (1995). Coisa julgada e litispendência em ações coletivas. Saraiva.

Jornal correio do povo. https://www.correiodopovo.com.br/not\%C3\%ADcias/geral/vazamento-de-\%C3\%B3leo-afeta-a-409-praias-do-nordeste-1.378843.

Lei $n^{\circ} 13.105$ de 16 de março de 2015. Institui o Código de Processo Civil. http://www.planalto.gov.br/CCIVIL_03/ ato 2015-2018/2015/lei/113105.htm.0.

Marconi, M.de A., \& Lakatos, E.M. (2003). Fundamentos de Metodologia Científica. (5a ed.). Atlas. 
Research, Society and Development, v. 10, n. 4, e46210414389, 2021

(CC BY 4.0) | ISSN 2525-3409 | DOI: http://dx.doi.org/10.33448/rsd-v10i4.14389

Maiolino, E. Z. (2005, maio). Coisa Julgada nas Ações Coletivas. Revista de Processo, DTRI20051336. Revista dos Tribunais. 123,60 -75.

Mendes, A. G. de C., \& Silva, L. C. P.da. (2018, julho-dezembro). Ações Coletivas Transnacionais. Revista de Processo, DTR/2018122729. Revista dos Tribunais. 8, $233-249$.

Mendes, A. G.de C., \& Silva, L. C. P. (2012, julho). A legitimação, a representatividade adequada e a certificação nos processos coletivos e as ações coletivas passivas. Revista de Processo, DTR|2012\44846. Revista dos Tribunais. 209, 243 - 264.

Souza Netto, J. L. de. (2012). A evolução da jurisdição para uma perspectiva transformadora: a necessária compreensão crítica da realidade. Revista do Instituto do Direito Brasileiro, 01(5), 3103 - 3135 .

Moreira, J.C. B. (1984). Temas de direito processual civil: terceira série. Saraiva.

Rocha, L.V. (2002, julho-setembro). Por uma conceituação de ação coletiva. Revista de Processo, DTRI20021349. Revista dos Tribunais. 107, 269 -277.

Santos, R. L. dos. (2009). Sindicatos e ações coletivas: acesso à justiça, jurisdição coletiva e tutela dos interesses difusos, coletivos e individuais homogêneos. (2a ed.), LTR.

Silva, J.A. da. (2003). Curso de Direito Constitucional Positivo. (22a ed.), Malheiros.

Talamini, E. (2015, março). Direitos individuais homogêneos e seu substrato coletivo: ação coletiva e os mecanismos previstos no código de processo civil de 2015. Revista de Processo, DTR 12015 2131. São Paulo: Revista dos Tribunais. 241, 337 -358.

Taruffo, M. Notes on the collective protection of rights. (2012). I Conferencia Internacional y XXIII Jornadas Iberoamericanas de derecho procesal: procesos colectivos class actions, Buenos Aires: International Association of Procedural Law y Instituto Iberoamericano de derecho procesal. p. 23-30.

Vitorelli, E. (2018, abril). Ações Coletivas Passivas: Porque elas não existem e nem deveriam existir. Revista de Processo, DTR|2018\10624. Revista dos Tribunais. 278, $297-335$.

Vitorelli, E. (2019). O Devido Processo Legal Coletivo: dos direitos aos Litígios Coletivos. Revista dos Tribunais.

Zavascki, T. (2016). Processo Coletivo. Tutela de Direitos Coletivos e Tutela Coletiva de Direitos. Revista dos Tribunais. 